\title{
The Role of Community in Black Identity Development and Occupational Choice
}

\author{
Nyla Stanford, Shelby Carlock and Fanli Jia *(D) \\ Department of Psychology, Seton Hall University, South Orange, NJ 07079, USA; nylastanford@gmail.com (N.S.); \\ shelby.carlock@student.shu.edu (S.C.) \\ * Correspondence: fanli.jia@shu.edu
}

Citation: Stanford, N.; Carlock, S.; Jia, F. The Role of Community in Black Identity Development and Occupational Choice. Societies 2021, 11, 111. https://doi.org/10.3390/ soc11030111

Academic Editor: Gregor Wolbring

Received: 12 July 2021

Accepted: 30 August 2021

Published: 10 September 2021

Publisher's Note: MDPI stays neutral with regard to jurisdictional claims in published maps and institutional affiliations.

Copyright: (c) 2021 by the authors. Licensee MDPI, Basel, Switzerland. This article is an open access article distributed under the terms and conditions of the Creative Commons Attribution (CC BY) license (https:// creativecommons.org/licenses/by/ $4.0 /)$.

\begin{abstract}
Black Americans have historically been excluded from societal associations and faced wavering instability in their households, forcing them to work together for their individual and collective well-being. In past research, more than half of Black American students enrolled in school opted to pursue social or educational careers. Findings suggest that Black Americans' occupational development is influenced by their family and community ties. In this conceptual paper, the foundation of the development of identity in African American culture is presented, as it relates to occupational decision-making. First, we discuss the influences of general identity development on occupational decision-making. Second, we argue that Black cultural identity is multidimensional, with strong community and family factors that play a special role in occupational choice. Third, we suggest future research paradigms to link racial identity, culture, and occupational choice among Black American students. By exploring the fundamental beliefs of Black cultural identity, and how they buffer against each other, Black American students will be better able to make occupational decisions.
\end{abstract}

Keywords: Black identity; occupation; Black American students; community; family

\section{Introduction}

Identity plays a significant role in the foundation of an individual's occupational development, especially for young adults. As adolescents transition into adulthood, exploration strongly influences this transition, as this period is especially important for establishing interests and developing plans for future careers. In choosing an occupation, people reflect on their potential for achievement and their desired level of stability [1]. The disproportionate representation of Black Americans in certain occupations, such as their overrepresentation in social and educational fields and their underrepresentation in STEM fields, calls for more research on occupational decision making in this community [2]. While some researchers have scraped the surface of Black identity, they have failed to dig into the deeply rooted African American culture from which Black identity grows. We are still lacking sufficient research on the relationship between occupational development and identity attainment among Black students.

An individual's life and purpose are developed through their integration with occupational development. Often interchangeable with vocation, an occupation is defined as having clarity in a direction of interest, one's capabilities, and one's aspirations [3]. Throughout adulthood, this development is not only about occupational achievement, but also the establishment of a continuous structure [3]. A misstep in the developmental process can lead to maladjustment and confusion, specifically in adolescence [4].

According to Christenson and Thurlow [5], occupational identity and social identity are related to meaningful contexts in life. In a recent study, the effects of lower socioeconomic status on students' occupational development were analyzed. Students tended to have less self-regulation and consistently drew comparisons between themselves and peers when it came to upward mobility in an occupation [6]. Thus, the critical theory of 
status-based identity uncertainty suggests tangible outcomes are drawn from environmental factors affecting foundational growth and occupational development. However, the literature surrounding the discourse has failed to proportionally investigate different cultural competencies related specifically to Black American identities.

Historically, Black Americans have been pushed out of societal associations and faced instability in their households, forcing communities of Black Americans to pull together for family and community well-being [7]. Moreover, collectivism and unity are highly regarded in "Afrocentric values" [8]. A beloved African proverb often repeated in the Black community is "I am because we are." In Witherspoon and Speight's [9] study, over half of Black college student participants chose occupations related to social or educational work. Findings from this study drew attention to the influence of familial and community ties on Black Americans' occupational development, and yet, there is a significant lack of research continuing the exploration of the theory. This article outlines the development of identity in occupation, as well as Black identity, which often affects occupational decisions. We first examine the literature on identity development and its influence on occupational decisions. More importantly, we explain how Black identity is multidimensional, how it distinctly contributes to occupational decisions, and review the literature demonstrating how Black American concepts of community and family aid in self-efficacy decision making. Finally, we suggest a few strategies to investigate how Black identity, community, and family could be studied holistically when considering the occupational decisions of Black Americans, in light of their experienced history of race-based social exclusion.

\section{Identity Development and Occupational Choice}

The original concept of identity was defined [10], with self-concept being almost solely defined by the experiences and values instilled in the primary years. Erikson [4], however, argues that different domains lay the foundation of one's identity. Erikson [4] defined these domains as ego identity, personal identity, and social identity, each of which can influence one's occupational identity. Social identity is determined by how well one's ideals match those of a group. A better description is how one makes sense of their role in society, and occupation takes precedent in that identity. Personal identity has a direct correlation with social identity, as it is composed of one's internal goals and beliefs, which are revealed through direct actions such as life choices and occupational decisions.

According to Erikson's model [4], there are eight distinct developmental stages from infancy to adulthood. The fifth stage, identity, is a critical catalyst. The fifth stage takes place when the individual moves from nurtured and idealized goals or representations to their own critical insights and desires [11]. Ultimately, the identities formed during childhood and those formed from peer views of social beliefs are reflected in one's new social relationships. An individual will face crises and achieve resolutions in various spheres, including their choice of occupation. While adolescents are beginning to think about their identities, emerging adults have more time available to explore their identities for the purposes of achieving success in careers, relationships, and the fulfilment of their life purpose [12].

During this stage, emerging adults' feelings towards identity fall within a bipolar continuum of achievement vs. diffusion. Based on Erikson's theory [4], the term achievement refers to one's wholeness as a result of proper exploration and commitment. Making decisions effectively is the hallmark of a successful individual. Diffusion refers to an apathetic disposition toward creating and exploring identity alternatives. In a state of complete diffusion, one has no ability to create a basic identity structure. Erickson believed that choice of an occupational domain is critical to emerging adults, as the choice of a career is critical to the progression of self-achievement.

Marcia [13] extended Erikson's theoretical framework and developed the concept of identity status, consisting of identity achievement, diffusion, foreclosure, and moratorium. The identity statuses follow a characteristic typology of the individual rather than a distinct progression of development [14]. However, these statuses were applied to the domains 
of occupation, religious beliefs, and political ideology. As previously explained, identity achievement is the wholeness of one's identity after proper exploration and commitment. Although identity achievement is not the end of the development, it reflects a peak of maturity and balanced thinking once it has been achieved [14]. Identity moratorium only achieves one portion-exploration. The moratorium is consumed with exploring alternatives, but no commitment. The flipside to moratorium is identity foreclosure. This status is depicted by set and committed goals with no exploration. Those who maintain this status demonstrate resistance to change and find comfort in their present circumstances [14]. The identity diffusion status does not explore or commit at all. There is a general apathetic attitude, and this can be reflected in maladjusted behaviors. Adults with this status struggle to formulate a secure sense of identity and make appropriate decisions about their lives. Security should not be confused with stability. Sellers and his colleagues showed that identity stability fluctuates over time and with changing situations, but this does not imply identity instability. An individual's status is a notary mark that expresses where they stand in terms of conceding their authentic self in different domains.

Identity statuses have been studied in the domain of occupation. According to Blustein et al. [15], one of the first studies examining the intertwined relationship of occupational self-efficacy used the differentiation of identity statuses. Blustein et al. [15] proposed a framework between identity status and career decidedness, suggesting that exploratory activity was associated with achievements and moratoriums, and with planning and commitment. Alternatively, diffusion is a rejection of the concept of exploring diverse interests, and foreclosure is a lack of engagement in the commitment to decisional selfefficacy. Their results emulated the hypothesis to some degree; achievement positively correlated with exploration because of set ego identity formation. The achievement of identity is the only status associated with occupational commitment. Further research should consider other ways to gain commitment, and cross analysis would have clarified the results in terms of relationships clearly, thus providing an opportunity for occupational development and identity formation to be integrated.

Pelerone et al. [16] investigated the relationship between identity and career decisions among Italian adolescents. A survey was administered to 417 students from Italian high schools, with three questionnaires assessing vocational interest, identity status, and decision-making style. The questionnaires used were the Ego Identity Process Questionnaire (EIPQ), the Self-Directed Search (SDS), and the General Decision-Making Style (GDMS), respectively. The literature has shown that the achievement of identity fosters independent decision-making with distinct interests. A high-profile identity would have a greater potential for discernment and stability in occupational interests, according to the proposed hypothesis. The second hypothesis contends that an individual with lowprofile identity status would make decisions based on external input, depending on the individual's own reasoning. It was found that identity status had a major impact on the differentiation of interests, and that having a strong identity aided in the initial exploration of interests. The initial exploration is important because it evolves the individual through the process of identity achievement. However, there were important limitations in the development of identities in their study due to the varying ages of participants.

As a precursor study to Pellerone et al. [16], in a study examining the relationship between identity status and self-efficacy when making career decisions, Nauta and Kahn [17] investigated the consistency and distinction of interests in the identity status models. A total of 111 college students, $86 \%$ of whom were Caucasian, took part in the study. They hypothesized that identities associated with commitment (achievement and foreclosure) would have higher career decision self-efficacy, and that the identities associated with the healthy exploration of interest (moratorium and achievement) would have more distinction and consistency. The results revealed that only identity achievement was associated with high career decision self-efficacy, and while foreclosure and moratorium had individual traits represented in career decision self-efficacy, lack of wholeness deferred self-efficacy. 
The notion of identity is relevant at every critical transition point in emerging adulthood, as discussed above. It is crucial that we understand how the achievement of identities impacts future career choices. As Erikson concluded, choices are largely shaped by beliefs and goals, which constitute a dichotomous identity structure. However, social, historical, and political contexts are less frequently discussed when considering an individual's identity and occupational development. The structural contingencies of society are inextricably linked with the individual, and one's identity cannot be achieved without it [18]. The highly racialized and stigmatized experiences of Black Americans influence fundamental decisions such as occupation choice. Excluding or removing this critical factor of identity development does not depict complete identity achievement, and fails to accurately examine individual development. In considering social, historical, and political contexts, Black cultural identity should be assessed as an important factor.

\section{History of Black Cultural Identity}

The foundation of African/Black psychology began in ancient Kemet (Egypt), central to the Maat philosophy abided by the natives. To achieve a pure and balanced soul, Maat prescribes guidelines and commands (42 areas of judgment). The Kemetic concept of the soul roughly parallels the European ideology of the mind, despite its explicit intertwining of spirituality [19]. There are seven dimensions of the soul or psychical system that follow the natural form of the human psyche. The human functioning paradigm sakhu, which means "understanding, illumination and soul of being," has roots in the original Eurocentric understanding of the psyche [20]. The African roots of Black psychology stem from the representation of the whole self, or soul, in its collective form. The foundations of Maat are heavily influenced by communal efforts, and the lack thereof reflects the deficits observed in the African psyche. This ancient context insinuates the long historical inquiry of Black psychological development. Even so, the first widely accepted conceptualizations of Black self-esteem did not become widely known until Westerners developed an interest in the phenomenon.

Mark of Oppression is one of the earliest works on the correlation between an oppressive, racial state and a low self-concept. In their book, Kardiner and Ovesey link discrimination inflicted upon Black people with inferior self-worth. Following this work, Jean Grambs [21] theorized that the manifestations of this perceived inferiority incite "Black-on-Black crime", unstable home dynamics, and dismal educational achievements [22]. Interestingly, these theories were developed without mention of the context of systematic racism that intentionally implements damaging beliefs.

Several researchers, including Horowitz [23] and Clarks [24], have examined how children perceive racial state and self-concept. They found that African American and white preschool age children alike preferred white dolls [23]. Clarks, corroborating Horowitz findings, argued that Black children's preference for white dolls was evidence of identity rejection [24]. However, research on this topic has been heavily criticized over the past three decades. In recent scholarship, it has been suggested that the early work of Horowitz and Clark did not reveal self-rejection, but rather a lack of differentiation between self and group identity in African Americans [24].

More recently, Black academics have reconstructed prior assumptions of Black selfworth into an authentic Black identity model. Cross [25] explains how Charles Thomas first introduced the concept of "negromacy," the confusion of self-worth dependent upon Eurocentric standards and beliefs for the self. He examined the relationship between white rejection of Black individuality and Black assimilation to whiteness. Similar to Grambs' position [21] of the environment sustaining the "white is right" perspective, Thomas emphasizes that negromacy protects and maintains the subjection of white superiority [25]. Cross [25] explained how Thomas used mental illness as a metaphor to indicate that Black Americans adapt to their double personalities and strive for recognition, for more than just acceptance, but rather prosperity in the same society from which they are excluded. His theory shifted Black identity away from deprecation and victimhood to a transitional 
journey from the suppression of full self. In overcoming this position, the Black individual aligns with the values and acceptance of their community and, most importantly, of themselves. Negromacy is overcome when one discovers their own Black identity. This rejects older models that emphasized only negative experiences of racism but instead emphasizes the importance and distinction of culture in Black identity.

William Cross [25] bridges this early formation into theory with Nigrescence. Nigrescence, more commonly known as the Black Identity model, acknowledges four stage-like periods that ultimately lead to Black identity internalization: pre-encounter, encounter, immersion/emersion, and finally internalization. While Thomas and Cross' theories are similar with respect to containing stage-like transitions, the difference that helped establish the theory as a reputable research process was acknowledging the period before the transformation. Thomas begins his theory at the point of transformation, while Cross [25] acknowledges the ignorance that generates a desire for wholeness. Black individuals were intended to follow the evolution of this model as they faced America's oppressive system. Quite clearly, it outlines the development of becoming Black [19]. The stages are as follows: Pre-encounter is the initial dissonance between an individual and their Blackness, often characterized as pro-white/anti-Black. Encounter is the second step, during which the individual's prior understanding of racial differences is challenged, usually by a personal experience. It inspires them to seek a deeper and more fulfilling understanding of their heritage. At this stage, a profound connection is made with Black culture. This supersedes the next step, immersion/emersion. With new knowledge, their vantage point has flipped to pro-Black/anti-white. The fourth step is internalization. Internalization is the processed pro-Black identity that involves finding fulfillment and the acceptance of non-Blacks [25].

However, Cross' original model has also been criticized because it tries to portray Black nationalism in a negative way [26]. To address the criticisms, Cross revised his model in 1995 [27] and 2001 [28]. In the revised model [27,28], there are two main changes: (a) a differentiation between the role that group identity plays and the personal identity role, and (b) a revision to the number of stages and identities within each stage. Specifically, Cross added three distinct identity clusters to the pre-encounter stage: assimilation identity, miseducation identity, and self-hatred identity [27]. In addition, as opposed to considering this stage of development as an identity with two components (e.g., pro-Black and antiwhite) [28]. Cross [26-28] later separated these identities as Black nationalism. In the final internalizing stage, Cross considered multicultural inclusiveness, embracing a Black identity as well as other identities such as racial, gender, and religious identities [28].

Another Black academic, Janet Helms [29], found the stages more stifling than extenuating the progression of Black identity, especially under oppressive conditions. Black identity is a subjective experience that shapes a person's understanding of and value for the group to which they belong. Individual experience should not be confused with individualism, which is still not ascribed to Black identity. More so, collectivism is experienced through several different worldviews, and those personal experiences shape the true evolution of one's identity [19]. Taking into account the differences between white racial identity and the identity of those of color, Helms [29] examined racial identity models that she proposed as a tool for analyzing racial identity. Between these two models, this type of collective identity development may contribute to the desire for overcoming negative attitudes towards minorities, in this case, Black identity. The Black identity process begins in the pre-encounter phase, which relies heavily on the oblivion of the true racialized state, and such internal suggestions change as the self-group or community emerges. Taking it a step further, due to societal racialized groupings, Black identity is impossible to develop without the enveloping of one's community influences. It derives a sense of belonging by integrating within and outside of the racial group [25].

The prior models of Cross and Helms have been the theoretical foundation for numerous studies of racial identity, and have profoundly influenced the works of Robert Seller. Sellers and his colleagues [30] designed the Multidimensional Model of Racial Identity (MMRI) to deconstruct the mainstream and underground approaches which were long 
used to understand the psychological processes and influences of racial identity, especially of Black identity. The model reconstructs the approaches by conceptualizing and operationalizing the findings that represented the significance and qualitative meaning of being in the Black community.

The Multidimensional Inventory of Black Identity was created to measure four dimensions: salience, centrality, regard, and ideology [30]. In the case of Black identity influencing occupational choice, ideology is important for understanding behaviors. Sellers et al. explained ideology in four philosophies: nationalist, oppressed minority, assimilation, and humanist $[27,30]$. These philosophies represent points on a continuum of racial salience and how the concept of race influences the concept of self. Sellers et al. showed that situational stimuli generated a varying level of salience with regard to the in group, whether or not the out group was disregarded. It is evident that generalizability of the MMRI or other models is complex due the extremely unique individual experiences of Black Americans collectively. What it means to be Black may be different to each person or in each situation, but due to the historical stigmatization of the group which has threatened to pull them apart [30], the behaviors of African Americans are usually derived from a place of heterogenous culture and homogenous desires to stick together.

\section{Black Cultural Identity, Sense of Community, and Occupational Choice}

Collectivism, as stated earlier, arises from the intergroup connection and responsibility to one another [8]. The socialization of community, especially intraracial community, is asserted early in life. As a result, interracial socialization may challenge early beliefs and prompt individuals to form their own communities. Research has found that Black students create counter-spaces (within school) to foster positive identity-affirming practices, such as having a safe space to speak on the concerns of racism and bond over culture-specific entities [31]. Carter [31] built a qualitative study around the theory of these spaces, in which Black students grouped into small communities, within their own racial identity, in a predominantly white high school. Nine high-achieving Black students participated in semi-structured interviews addressing their relationship with the school, their behaviors in school, culture appreciation in school, and their future plans. The results revealed a "fictive kinship" among the Black students. Fictive kinship, a common conceptual practice among Black Americans, is a relationship that aligns based on a "social, cultural and/or economical foundation" [31]. It is imperative to have these formal and informal meetings, which serve to reinforce the community-based value system and internalize Black identity.

Apart from the community being a significant pillar in Black identity, the family is a core part of Black identity. Keber [32] wrote "family and kin groups form a network of relationships that, in a sense, establish the community." This means that the families who generate the ideas of Black identity are essentially carried over into the creation of a community that defines those ideas. Demo and Hughes [33] reported that Black identity is dependent on the variations of how one experiences family, community, and society. These experiences have psychological effects on both personal and group identity. One's sense of being connected to a group, either in terms of racial group evaluation or separatism, is determined by their group identity. It is important to note that religiosity also plays a key role in creation of community and development of Black identity. Religious involvement includes the gatherings of Black Americans, through which communities have historically developed fictive kinships among people of African descent. Demo and Hughes [33] developed an empirical study examining the roles of friendships, family relationships, religious involvement, and socioeconomic attainment in determining an individual's sense of self. The sample consisted of 2107 Black American students over the age of 18, gathered from the National Survey of Black Americans (NSBA). Despite the correlations not revealing the same connecting catalyst, the variables were all positively related.

How does this engrained community connection affect the occupational development of Black students? Most studies have explored only the relationship between racialized 
identity and occupational salience, and how the identity helps the student to either excel or deplete their educational experience [34]. Few studies have examined the foundational blocks of Black identity to understand how Black students develop their vocation and interests. Collectivism and education are not entirely based on choosing a career that benefits the community. Nevertheless, the entire process of applying and completing higher education signifies group empowerment [8]. To understand the community aspect of occupational development, all the ripple effects must be understood first individually, then as a whole. This influence is seen in field choice, as nearly $20 \%$ of Black American students receive a degree in social science (National Science Foundation [35]). However, this statistic includes discrimination of STEM programs and imposter syndrome imposed on Black students [36]. A qualitative study by Carson [8] offers another perspective from within the Black community regarding higher education, gleaning word-of-mouth about collectivism. A commonality in purpose for higher education is the success of one benefitting many, referring back to "I am because we are." Taking the time and effort to attend college for the purpose of pursuing a career is a form of collectivism with the community at its core.

The development of identity is directly related to the development of vocational tendencies. According to Helms [29], racial identity can predict interest and career values, connecting the influence of the community on Black identity. The contingency of the Black experience can promote or deter career self-efficacy. Traditionally, research has focused more on the differences of career choices of Black individuals compared to their white counterparts, rather than on how Black identity influences occupational choices. Race salience, the extent to which an individual believes race affects occupational choice, determines, along with racial identity, how an individual conceptualizes occupational interest. Furthermore, the reflection of oneself in a work environment is how one will see themselves there. Research has also shown that without exemplars in a given occupational field, individuals are less likely to see themselves in that occupation. There becomes a natural pull towards occupations where individuals believe they can achieve because of what others in their community have achieved before them. This reinforces the idea that community is a strong determinant of occupational choice.

Research has proven that having a strong identity, while it can help Black Americans develop a substantial vocational persona, can also alter their efficacy skills as a function of experiencing racism. The moderating effect of racial discrimination can weaken selfefficacy and push Black Americans toward more social service occupations and supportive positions. The uncertainty of the "glass ceiling" effect for Black Americans can reduce the perception of vocational opportunities $[9,37]$. These occupational stereotypes are focused on social and enterprising careers-ones that provide for their communities. In terms of occupation choices and African Americans, this was the original assuming context, but it seems there is an underlying connection between Black identity, community-based organization, and occupational development that does not exclusively center negatively. Walker and Tracy [2] found that Black Americans with strong internalized identities tended to be more interested in social and entrepreneurial occupations.

\section{Future Suggestion and Conclusions}

The goal of the aforementioned research is to establish the foundation of community in Black identity, and how community affects the occupational development of Black American students. While studies connect identity and occupational development, there is little research on how race identity, specifically Black identity, affects the development of occupation decisions in underrepresented groups. Research in the last two decades has been sorely lacking, and not just in occupational development. There is a substantial gap between 1985 and the current period in empirical psychological research on African Americans. This gap leaves questions about the evolving psychological well-being of Black Americans unanswered, and reinforces white Americans as a psychological standard. More specifically, 
it leaves questions on the effect of buffering of Black identity on occupational development and the buffering of community on the construction of Black identity unanswered.

Based on the research on race identity, it has been shown that occupational development can be related to several aspects of occupational identity, such as pre-encounter mindsets and career decidedness [38]. First of all, it would be helpful to gain a better understanding of Black identity from a 21st century perspective. The majority of identity research comes from the work of Helms and Cross. Despite the usefulness of their work, their theories on Black identity only focus on how it is acquired from ignorance, not what influences its creation. Those influences, such as family and community, could reveal more information about Black identities and how they shift into other identities such as occupational identities.

A second suggestion follows the pattern of research conducted on the development of occupations among Black students. Black Americans have statistically been shown to cluster into service-based careers (counselors, home health, personal care aids, hairstylists, and concierges, etc.) [9,39]. According to the Annual Averages for Employed Person by Occupation and Race from the U.S. Bureau Labor Statistics in 2020 [39], Black Americans made up $6.0 \%$ of those in architecture and engineering occupations (78\% white counterparts); $6.5 \%$ in life and physical science occupations (75.1\% white counterparts); $9.7 \%$ in management (78.7\% white counterparts); and $10.5 \%$ in business and financial operations (78\% white counterparts). While Black Americans have become more visible in the workplace, they continue to face many obstacles that impede their professional growth, such as the effects of long-term systemic racism and a lack of exemplars.

There is a perceptible connection between Black identity and community when we refer to the values that reflect the importance of cooperation and community survival, but past research has only vigorously examined the relationships of traditional choices among Black students [9]. Family, as an ideology in Black studies, is not just biological. Black individuals are in a position where sharing and interdependence are essential for survival. Often, Black families expand with extended family because of a certain elasticity that is at the core of a Black family's foundation [40]. This embedded communal trait that follows throughout childhood and into adulthood nearly negates Erikson's theory of identity which suggests that interaction with peers is the catalyst of who we are. The idea of community never falters through interactions, which is shown by patterns of occupational choice. Failing to go beyond surface-level interpretations of Black occupational identity isolates possible causal variables, including community. Including that variable within research regarding Black students and occupational development could provide more evidence explaining why Black students choose certain career paths.

Third, future research examining Black identity through the perspective of community must include a gender dimension. Despite studies indicating that African American men have greater confidence in career decision-making self-efficacy, African American women have reported a greater significance than their male counterparts [40,41]. This could be a reflection of the androgynous effect of Black women commonly being the primary household provider. There is less of a dependency on marriage for survival due to the detachment from the stigma of working women, usually vicariously learned from their mothers before them. The psychological buffers for gendered racism manifest themselves as survival techniques to cope with the dual effects of sexism and racism. Black women frequently do not hesitate to work for financial independence and self-reliance because of the "strong Black woman" stereotype, which can promote strengthening career selfefficacy but is associated with extreme stress levels. The ideology of working harder comes from overpreparing, which leads to better outcomes. Lack of those outcomes can also lead to African American women disengaging from career-related tasks. On the other hand, conflicting views instilled in adolescence with performance accomplishments, vicarious learning, and verbal persuasion can deter African American girls from vocational discovery $[42,43]$. 
Another stereotype of Black women in the workplace is "Mammyism" [44-46]. Privileged whites historically used these characteristics to portray Black women as "devoted" domestic workers who aim to sacrifice their lives for their white bosses (often only addressed by the white woman) as nonthreaded survival strategies. These Black women were taken from their own homes to cater to white families and often forced to neglect their own [46]. According to Abdullah [44], Mammyism can damage Black women's mental health. Black women could adopt a Mammy role as a means of coping with survival threats. Professional women may believe that they have to fit the profile of the Mammy in their professional setting in order to be acceptable and nonthreatening in the workplace $[45,46]$. Though they are excellent professionals, Black women's nurturing abilities seem to be viewed as more important than their professional skills. Black women who fit the Mammy stereotype are therefore still seen in the workplace in supportive positions instead of leadership positions [45,46].

Whether strengthening or deteriorating, research shows lingering connections are made between strong racial identities, sexism, and career self-efficacy skills, but has yet to look at how they operate together in the development of a complete occupational identity [47]. Using gender as a variable could reveal a causal relationship between occupational development and community in Black identity, and answer questions about its effect on the duality of race and gender. Sellers and his colleagues moderately expanded on the paradigms of identifying as both Black and as a woman [30]. While their model focused on understanding the perception of self with regard to racial salience, it also suggested how this affects the salience of occupational identities, as we have in this conceptual paper, and also of gender identities. They explained that an individual who identifies as a woman and as Black experiences each identity together and separately, at the same time [30]. Past research has shown that there may be a hierarchy to multiple identities, but their model explored the importance of this intersectionality, instead of how one identity may be more important than another $[30,45]$.

Given this context, a woman whose race and gender identities are both salient is "more likely to incorporate gender in her conceptualization of what it means to be Black" [30]. This is a complex concept that requires more research to emphasize the meaning of not only being Black, but of being a Black woman. Every individual who identifies as Black experiences Blackness through their own unique perspective. Thus, Black women experience being Black through two dependently independent perspectives. These experiences are intricately affected by the historical and modern life experiences that are unique to the Black American community. Culture and community are influential factors which determine how salient each identity (Black, woman, etc.) is, and how they influence each other. What it means to be Black is not defined as points of development but as a continuum. As women struggle to prosper in occupations where they face both the "glass ceiling" and the "glass staircase", and for women to make healthy occupational decisions in a society where they continue to face discrimination and stigmatization for both their race and gender, it is more relevant and necessary than ever to understand how community affects the identities of Black women.

This conceptual paper was intended to find the relationship between the core principle of community in Black identity and occupational development. While representative career choices have given support and evidence to key theories about vocational development in the Black community, they have not answered the more pressing questions of why. Community evidently but indirectly affects day-to-day choices, but more research needs to emphasize this connection. Exploring the core beliefs of Black identity and how they buffer against one another will assist in the subgroup's decision making (e.g., choosing an occupation). The literature has shown the possibility of the effects of foundational beliefs on identity without the restrictions of stage-like entities.

Author Contributions: Conceptualization, N.S. and F.J.; formal analysis, N.S.; investigation, N.S.; writing—original draft preparation, N.S.; writing—review and editing, N.S.; S.C.; F.J.; supervision, F.J. All authors have read and agreed to the published version of the manuscript. 
Funding: This research received no external funding.

Conflicts of Interest: The authors declare no conflict of interest.

\section{References}

1. Clausen, J. Adolescent competence and the shaping of the life course. Am. J. Sociol. 1991, 96, 805-842. [CrossRef]

2. Walker, T.L.; Tracey, T. The role of future time perspective in career decision-making. J. Vocat. Behavior. 2012, 81, 150-158. [CrossRef]

3. Skorikov, V.B.; Vondracek, F.W. Occupational Identity. In Handbook of Identity Theory and Research; Schwartz, S.J., Luyckx, K., Vignoles, V.L., Eds.; Springer: New York, NY, USA, 2011; pp. 693-714. [CrossRef]

4. Erikson, E.H. Identity: Youth and Crisis; W.W. Norton \& Company: New York, NY, USA, 1968.

5. Christenson, S.L.; Thurlow, M.L. School Dropouts: Prevention Considerations, Interventions, and Challenges. Curr. Dir. Psychol. Sci. 2004, 13, 36-39. [CrossRef]

6. Destin, M.; Rheinschmidt-Same, M.; Richeson, J.A. Status-Based Identity: A Conceptual Approach Integrating the Social Psychological Study of Socioeconomic Status and Identity. Perspect. Psychol. Sci. 2017, 12, 270-289. [CrossRef] [PubMed]

7. Williams, J. A Common Destiny: Blacks and American Society; National Academy Press: Washington, DC, USA, 1989.

8. Carson, L.R. "I am because we are:" collectivism as a foundational characteristic of African American college student identity and academic achievement. Soc. Psychol. Educ. 2009, 12, 327-344. [CrossRef]

9. Witherspoon, K.M.; Speight, S.L. An Exploration of African Americans' interests and self-efficacy beliefs in traditional and nontraditional careers. J. Black Stud. 2009, 39, 888-904. [CrossRef]

10. Lauzun, G. Sigmund Freud: The Man E His Theories; Souvenir Press: London, UK, 1965.

11. Gillard, C.; Higgs, P. Connecting Life Span Development with the Sociology of the Life Course: A New Direction. Sociology 2016, 50, 301-315. [CrossRef] [PubMed]

12. Kaur, N.; Singh, K. Identity Formation: Role of Academic Achievement and Gender among College Students. MIER J. Educ. Sci. Trends Pract. 2019, 9, 165-175.

13. Marcia, J.E. The Ego Identity Status Approach to Ego Identity. Ego Identity 1993, 3-21. [CrossRef]

14. Schwartz, S.J. The Evolution of Eriksonian and, Neo-Eriksonian Identity Theory and Research: A Review and Integration. Identity 2001, 1, 7-58. [CrossRef]

15. Blustein, D.L.; Devenis, L.E.; Kidney, B. Relationship between the identify formation process and career development. J. Couns. Psychol. 1989, 36, 196-202. [CrossRef]

16. Pellerone, M.; Passanisi, A.; Bellomo, M.F. Identity development, intelligence structure, and interests: A cross-sectional study in a group of Italian adolescents during the decision-making process. Psychol. Res. Behav. Manag. 2015, 8, 239-249. [CrossRef]

17. Nauta, M.M.; Kahn, J.H. Identity Status, Consistency and Differentiation of Interests, and Career Decision Self-Efficacy. J. Career Assess. 2007, 15, 55-65. [CrossRef]

18. Syed, M.; Fish, J. Revisiting Erik Erikson's legacy on culture, race, and ethnicity. Identity Int. J. Theory Res. 2018, 18, 274-283. [CrossRef]

19. Kambon, K.K. African/Black Psychology in the American Context: An African-Centered Approach; Nubian Nation Publications: Tallahassee, FL, USA, 1998.

20. Akbar, N. Africentric social science for human liberation. J. Black Stud. 1984, 14, 395-414. [CrossRef]

21. Bank, J.A.; Grambs, J. Black Self-Concept: Implications for Education and Social Science; McGraw-Hill Book Company: New York, NY, USA, 1972.

22. Belgrave, F.Z.; Reed, M.C.; Plybon, L.E.; Butler, D.S.; Allison, K.W.; Davis, T. An Evaluation of Sisters of Nia: A Cultural Program for African American Girls. J. Black Psychol. 2004, 30, 329-343. [CrossRef]

23. Horowitz, E.L. The Development of Attitude Toward the Negro. Doctoral Dissertation, Columbia University, New York, NY, USA, 1936.

24. Clark, K.B.; Clark, M.P. The development of consciousness of self and the emergence of racial identification in Negro preschool children. J. Soc. Psychol. 1939, 10, 591-599. [CrossRef]

25. Cross, W.E. The Thomas and Cross models of psychological nigrescence: A review. J. Black Psychol. 1978, 5, 13-31. [CrossRef]

26. Vandiver, B.J.; Cross, W.E.; Worrell, F.C.; Fhagen-Smith, P.E. Validating the Cross Racial Identity Scale. J. Couns. Psychol. 2002, 49, 71. [CrossRef]

27. Cross, W.E., Jr. The psychology of nigrescence: Revising the Cross model. In Handbook of Multicultural Counseling; Ponterotto, J.G., Casas, J.M., Suzuki, L.A., Alexander, C.M., Eds.; Sage Publications: New York, NY, USA, 1995; pp. 93-122.

28. Cross, W.E., Jr.; Vandiver, B.J. Nigrescence Theory and Measurement: Introducing the Cross Racial Identity Scale (CRIS). In Handbook of Multicultural Counseling; Ponterotto, J.G., Casas, J.M., Suzuki, L.A., Alexander, C.M., Eds.; Sage: Thousand Oaks, CA, USA, 2001; pp. 371-393.

29. Helms, J.E. Racial identity and career assessment. J. Career Assess. 1994, 2, 199-209. [CrossRef]

30. Sellers, R.M.; Smith, M.A.; Shelton, J.N.; Rowley, S.A.J.; Chavous, T.M. Multidimensional Model of Racial Identity: A Reconceptualization of African American Racial Identity. Personal. Soc. Psychol. Rev. 1998, 2, 18-39. [CrossRef] 
31. Carter, D. Why the Black Kids Sit Together at the Stairs: The Role of Identity-Affirming Counter-Spaces in a Predominantly White High School. J. Negro Educ. 2007, 76, 542-554. Available online: http:/ /www.jstor.org/stable/40037227 (accessed on 18 March 2021).

32. Keber, H.P. Spout Spring: A Black Community. Peter Kunkel, Sara Sue Kennard. Am. Anthropol. 1974, 76, 149-150. [CrossRef]

33. Demo, D.H.; Hughes, M. Socialization and Racial Identity among Black Americans. Soc. Psychol. Q. 1990, 53, 364. [CrossRef]

34. Cokley, K. An Investigation of Academic Self-Concept and its Relationship to Academic Achievement in African American College Students. J. Black Psychol. 2000, 26, 148-164. [CrossRef]

35. National Science Foundation. 2019. Available online: https://www.nsf.gov/statistics/women/ (accessed on 10 August 2021).

36. Archer, L.; Dewitt, J.; Osborne, J. Is Science for Us? Black Students' and Parents' Views of Science and Science Careers. Sci. Ed. 2013, 99, 199-237. [CrossRef]

37. Tovar-Murray, D.; Jenifer, E.S.; Andrusyk, J.; D'Angelo, R.; King, T. Racism-Related Stress and Ethnic Identity as Determinants of African American College Students' Career Aspirations. Career Dev. Q. 2012, 60, 254-262. [CrossRef]

38. Byars-Winston, A. The Vocational Significance of Black Identity: Cultural Formulation Approach to Career Assessment and Career Counseling. J. Career Dev. 2010, 37, 441-464. [CrossRef]

39. U.S. Bureau Labor Statistics. The Annual Averages for Employed Person by Occupation and Race. 2020. Available online: https:/ / www.bls.gov/cps/cpsaat11.htm (accessed on 10 August 2021).

40. Littlejohn-Blake, S.; Darling, C. Understanding the Strengths of African American Families. J. Black Stud. 1993, $23,460-471$. [CrossRef]

41. Rollins, V.B.; Valdez, J.N. Perceived Racism and Career Self-Efficacy in African American Adolescents. J. Black Psychol. 2006, 32, 176-198. [CrossRef]

42. Donovan, R.A.; West, L.M. Stress and Mental Health: Moderating Role of the Strong Black Woman Stereotype. J. Black Psychol. 2015, 41, 384-396. [CrossRef]

43. Hackett, G.; Byars, A.M. Social Cognitive Theory and the Career Development of African American Women. Career Dev. Q. 1996, 44, 322-340. [CrossRef]

44. Abdullah, A.S. Mammy-ism: A Diagnosis of Psychological Misorientation for Women of African Descent. J. Black Psychol. 1998, 24, 196-210. [CrossRef]

45. Reynolds-Dobbs, W.; Thomas, K.M.; Harrison, M.S. From Mammy to Superwoman: Images That Hinder Black Women's Career Development. J. Career Develop. 2008, 35, 129-150. [CrossRef]

46. Shambley-Ebron, D.Z.; Boyle, J.S. New Paradigms for Transcultural Nursing: Frameworks for Studying African American Women. J. Transcult. Nurs. 2004, 15, 11-17. [CrossRef]

47. Lease, S.H. Factors Predictive of the Range of Occupations Considered by African American Juniors and Seniors in High School. J. Career Dev. 2006, 32, 333-350. [CrossRef] 